\title{
Updated ranges of the Vulnerable cheetah and Endangered African wild dog in Angola
}

\author{
Pedro Monterroso, Filipe Rocha, Stefan van Wyk, Telmo António \\ Milcíades Chicomo, Selma Kosmas, Fernanda Lages \\ Ezequiel Fabiano and RaQuel Godinho
}

\begin{abstract}
The civil unrest that ravaged Angola for nearly 30 years took a heavy toll on the country's wildlife, and led to a lengthy absence of reliable information for many threatened species, including the cheetah Acinonyx jubatus and African wild dog Lycaon pictus. Using camera trapping we assessed the status of these two species in two areas of southern Angola, and complemented our findings by reviewing recent survey reports and observations to provide an update on the species' status. We found unequivocal evidence that African wild dogs are resident and reproducing in Bicuar National Park, where cheetahs appear to be absent. Conversely, cheetahs may be resident in western Cuando Cubango province, where African wild dogs may only be transient. Based on these and other recent records in Angola, we recommend a revision of these species' distribution ranges and note the need for monitoring of these remnant populations and for appropriate attention to any threats.
\end{abstract}

Keywords Acinonyx jubatus, Angola, cheetah, conservation status, distribution, Lycaon pictus, African wild dog, southern Africa

Supplementary material for this article is available at doi.org/10.1017/So030605319000966

$\mathrm{D}$ espite Angola's high biodiversity, the political unrest during 1975-2002 took a heavy toll on its wildlife, which suffered from widespread poaching and bushmeat

Pedro Monterroso (Corresponding author, (D) orcid.org/0000-0002-79113651), Filipe Rocha*, Selma Kosmas $\dagger$ and Raquel Godinho* ${ }^{*}$ (D) orcid.org/ 0000-0002-4260-4799) Centro de Investigação em Biodiversidade e Recursos Genéticos, Universidade do Porto, Campus de Vairão, R. Padre Armando Quintas, Vairão, 4485-661, Portugal

E-mail pmonterroso@cibio.up.pt

Stefan van Wyk Cuatir Private Reserve, Cuangar, Angola

Telmo António, Milcíades Chicomo and Fernanda Lages Instituto Superior de Ciências da Educação da Huíla, Lubango, Angola

Ezequiel Fabiano Department of Wildlife Management and Ecotourism, University of Namibia, Katima Mulilo, Namibia

*Also at: Departamento de Biologia, Faculdade de Ciências, Porto, Portugal $\dagger$ Also at: Department of Wildlife Management and Ecotourism, University of Namibia, Katima Mulilo, Namibia

\$Also at: Department of Zoology, University of Johannesburg, Johannesburg, South Africa

Received 12 March 2019. Revision requested 13 June 2019

Accepted 7 August 2019. First published online 12 February 2020. hunting (Huntley, 2017). Although little is currently known about the status and trend of most Angolan wildlife populations, iconic and threatened species such as the cheetah Acinonyx jubatus and African wild dog Lycaon pictus are presumed to have suffered drastic declines and range contractions (Woodroffe \& Sillero-Zubiri, 2012; Durant et al., 2015). However, the Angolan government has recently shown signs of political will to improve knowledge of the country's biodiversity, including for the large carnivore species.

Globally, the African wild dog and cheetah are categorized as Endangered and Vulnerable, respectively, on the IUCN Red List because of population declines, range loss and the fragmentation of populations (Woodroffe \& Sillero-Zubiri, 2012; Durant et al., 2015). Although historical records indicate that both species formerly occurred widely in Angola (Beja et al., 2019), the majority of the country is currently classified as unknown range for both species (Fig. 1; IUCN/SSC, 2015). Updated knowledge about the distribution, abundance and population dynamics of both species, and any threats, is required for conservation planning.

Under the scope of ongoing institutional research and advanced training programmes, we surveyed c. $360 \mathrm{~km}^{2}$ in Bicuar National Park, which lies in the transition between the Angolan Miombo Woodlands and Zambezian baikiaea woodlands ecoregions (Olson et al., 2001) in the province of Huíla, and c. $300 \mathrm{~km}^{2}$ in Cuatir Private Reserve in western Cuando Cubango province, along the Cuatir river, one of the main tributaries of the Cubango (Okavango) river on its Angolan side, also in the Zambezian baikiaea woodlands ecoregion (Olson et al., 2001).

We deployed camera-trapping stations uniformly spaced at c. $2 \mathrm{~km}$ in the core of each study area using three camera-trap models: Hyperfire $\mathrm{HC} 6 \mathrm{oo}$ and $\mathrm{HF}_{2} \mathrm{X}$ Hyperfire 2 (Reconyx, Holmen, USA), and Cuddeback Model 1231 (Cuddeback, De Pere, USA). Fifty-one camera traps were deployed in Bicuar National Park during July 2017-June 2018 (Supplementary Fig. 1), and 43 traps in Cuatir Private Reserve during June-December 2018 (Supplementary Fig. 2). Cameras were inspected every 2 months. Additional records were obtained in Cuatir Private Reserve from unstructured surveys with six camera traps (Moultrie MP8, EBSCO Industries Inc., Birmingham, USA) during August 2013December 2018. Additional recent records of the cheetah and African wild dog in Angola were obtained by reviewing surveys reports and the Global Biodiversity Information 


\section{(a) Cheetah}

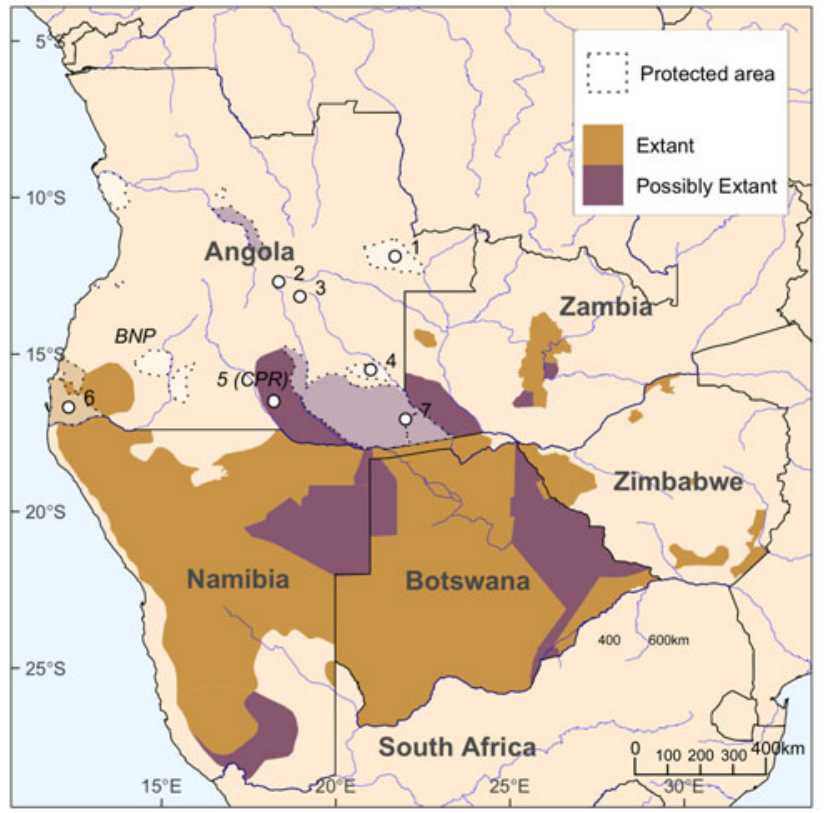

(b) African wild dog

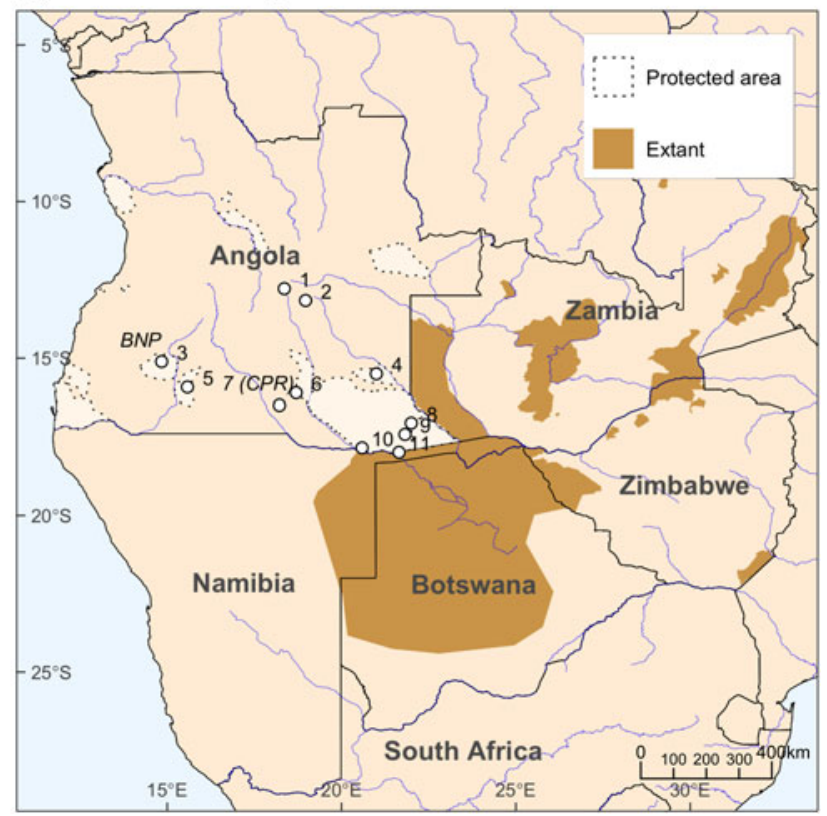

Fig. 1 Distribution status (IUCN/SSC, 2015) of (a) the cheetah Acinonyx jubatus in Angola, Namibia, Zambia, Zimbabwe and Botswana (Durant et al., 2015), and of recent (2008-2018) records in Angola (1, Purchase et al., 2007; 2,3, Taylor et al., 2018; 4,7, Funston et al., 2017; 5, this study; 6, Marker et al., 2010, Bruce Bennett, pers. obs., 2017), and (b) the African wild dog Lycaon pictus in Angola, Namibia, Zambia, Zimbabwe and Botswana (Woodroffe \& Sillero-Zubiri, 2012), and recent (2008-2018) records in Angola (1, BP Geological survey team, pers. obs., 2009; 2, Taylor et al., 2018; 3, this study, Overton et al., 2016, Fabiano et al., 2017; 4,8, Funston et al., 2017; 5, Overton et al., 2016; 6, John Mendelsson, pers. obs., 2012; 7, this study; 9-11, Veríssimo, 2008). Study sites: BNP, Bicuar National Park; CPR, Cuatir Private Reserve.

Facility database (GBIF, 2019; Purchase et al., 2007, Veríssimo, 2008, Marker et al., 2010, Overton et al., 2016, Fabiano et al., 2017, Funston et al., 2017, Taylor et al., 2018). We considered as independent any camera-trapping detections within 30 minutes, unless animals were unambiguously identified (Rich et al., 2017).

In Bicuar National Park we recorded 16 independent detections of two African wild dog groups over a total of 14,232 trapping-days. We were able to assign 15 individuals to one group and three to the other. African wild dogs were detected consistently throughout the sampling period at a mean detected group size of $3.6 \pm S D$ 2.6. No cheetahs were detected.

In Cuatir Private Reserve we obtained 13 independent detections of at least two cheetah individuals and no detections of African wild dogs over a total of 5,173 trappingdays of systematic surveying. Unstructured camera trapping provided records of an individual cheetah in July 2014, and a coalition of two male cheetahs in October 2017. We were not able to match any of these cheetahs with those of the 2018 survey. A group with $\geq 4$ African wild dog individuals was detected in July, August and October 2014, and another of $\geq 5$ individuals in October 2016.

Our findings build on recent surveys that indicate the occurrence of cheetahs and African wild dogs in LuengueLuiana and Mavinga National Parks (Funston et al., 2017), and in the Cuanavale and Cuito river catchments (Taylor et al., 2018; Fig. 1). African wild dogs have also been observed in Bicuar National Park by Overton et al. (2016) and Fabiano et al. (2017), and in Mupa National Park (Overton et al., 2016) and Mucusso Reserve (Veríssimo, 2008), and cheetahs in and around Iona and Cameia National Parks (Purchase et al., 2007; Marker et al., 2010). We found no records of cheetahs or African wild dogs for 2008-2018 in Angola in the Global Biodiveristy Information Facility.

Our findings indicate that the African wild dog's range as currently delimited (IUCN/SSC, 2015), should be extended c. $750 \mathrm{~km}$ further west-north-west from the Angolan/ Namibian border, beyond the Cunene river and including Bicuar National Park. As the species has been regularly detected in the Park since at least 2015, this complies with IUCN/SSC (2015) criteria as an area of African wild dog residency, with groups of $\geq 10$ individuals and breeding confirmed through multiple observations of groups with pups, made by park rangers in 2016 (Overton et al., 2016; Fabiano et al., 2017). It is likely that other large extents of good quality habitat in Angola also harbour resident populations, and further monitoring to assess presence and residency status are required. Cheetahs have been observed regularly in the lower Angolan range of the Cubango river, and also in south-eastern, south-western and central-eastern Angola in the provinces of Namibe, Cuando Cubango and 
Moxico (Marker et al., 2010; Funston et al., 2017; Taylor et al., 2018; Fig. 1). These reports suggest that IUCN's classification of the south-western Angolan range for the cheetah should be changed from Possibly Extant to Extant.

Our findings will support the new political willingness in Angola to invest in wildlife conservation strategies and will help to unlock conservation funding for the cheetah, African wild dog and other carnivores. Given that the majority of the distribution of these two species potentially falls outside protected areas where they are more susceptible to anthropogenic threats, we emphasize the urgency of identifying remnant populations in Angola and quantifying any threats to the species.

Acknowledgements We thank the Instituto Nacional da Biodiversidade e Áreas de Conservação for permits, José Maria Kandungo for logistic support in Bicuar National Park, Fernando Calunga and park rangers Fernando Tchacaca, Tchimbuale Cambuta, Ombili, José Manuel Tchipuapua and José Maria Alves for their assistance during fieldwork, and Bruce Bennett for data sharing in Iona National Park. PM was supported by UID/BIA/50027/2019 with funding from FCT/MCTES through national funds. FR, SK and RG were supported by the Portuguese Foundation for Science and Technology (PD/BD/114030/2015, PD/BD/142825/2018, IF/00564/2012). TM and MC were supported by the German Federal Ministry of Education and Research SASSCAL project (PN 01LG1201 M). This research was conducted within the UNESCO Chair Life on Land.

Author contributions Study design: PM, RG; fieldwork: all authors; data analysis: PM, FR; writing: PM, with inputs from all authors.

\section{Conflicts of interest None.}

Ethical standards This research abided by the Oryx guidelines on ethical standards.

\section{References}

Beja, P., Pinto, P.V., Verissimo, L., Bersacola, E., Fabiano, E., Palmeirim, J.M. et al. (2019) The mammals of Angola. In Angolan Biodiversity: a Modern Synthesis (eds B.J. Huntley, V. Russo, F. Lages \& N. Ferrand), pp. 357-443. Springer Nature, Cham, Switzerland.

Durant, S., Mitchell, N., Ipavec, A. \& Groom, R. (2015) Acinonyx jubatus. In The IUCN Red List of Threatened Species 2015. dx.doi.org/ 10.2305/IUCN.UK.2015-4.RLTS.T219A50649567.en [accessed 7 October 2019].
Fabiano, E.C., Álvares, F., Kosmas, S., Godinho, R. \& Castro, I. (2017) The Conservation Status of the Endangered African Wild Dogs in Angola: an Historical and Contemporary Perspective. Angola Carnivore Project, Mulilo, Namibia.

Funston, P., Henschel, P., Petracca, L.S., Maclennan, S.D., Whitesell, C., Fabiano, E. \& Castro, I. (2017) The Distribution and Status of Lions and Other Large Carnivores in Luengue-Luiana and Mavinga National Parks, Angola. KAZA TFCA Secretariat, Kasane, Botswana.

GBif (Global Biodiversity Information Facility) (2019) gbif. org [accessed 2O June 2019].

Huntcey, B.J. (2017) Wildlife at War in Angola: the Rise and Fall of an African Eden. Protea Boekhuis, Pretoria, South Africa.

IUCN/SSC (2015) Review of the Regional Conservation Strategy for the Cheetah and African Wild Dogs in Southern Africa. IUCN/SSC \& Range Wide Conservation Program for Cheetah and African Wild Dogs, Gland, Switzerland.

Marker, L.L., Fabiano, E. \& NGhikembua, M. (2010) A Rapid Ecological Survey in the Iona National Park, Namibe, Angola. Internal Report, Cheetah Conservation Fund, Otjiwarongo, Namibia.

Olson, D.M., Dinerstein, E., Wikramanayake, E.D., Burgess, N.D., Powell, G.V.N., Underwood, E.C. et al. (2001) Terrestrial ecoregions of the world: a new map of life on Earth. Bioscience, 51, 933-938.

Overton, J., Fernandes, S., Elizalde, D., Groom, R. \& Funston, P. (2016) A Large Mammal Survey of Bicuar and Mupa National Parks, Angola. With Special Emphasis on the Presence and Status of Cheetah and African Wild Dogs. National Institute of Biodiversity and Conservation Areas/Range Wide Conservation Program for Cheetah and African Wild Dogs, Luanda, Angola.

Purchase, G., Marker, L., Marnewick, K., Klein, R. \& Williams, S. (2007) Regional assessment of the status, distribution and conservation needs of cheetahs in Southern Africa. Cat News, 3, 44-46.

Rich, L.N., Davis, C.L., Farris, Z.J., Miller, D.A.W., Tucker, J.M., Hamel, S. et al. (2017) Assessing global patterns in mammalian carnivore occupancy and richness by integrating local camera trap surveys. Global Ecology and Biogeography, 26, 918-929.

Taylor, P.J., Neef, G., Keith, M., Weier, S., Monadjem, A. \& PARKER, D.M. (2018) Tapping into technology and the biodiversity informatics revolution: updated terrestrial mammal list of Angola, with new records from the Okavango Basin. ZooKeys, 779, 51-88.

Veríssimo, L.N. (2008) Mucusso Reserve. Larger Mammals Assessment. Preliminary, unpublished report. United States Agency International Development, Washington, DC, USA.

Woodroffe, R. \& Sillero-Zubiri, C. (2012) Lycaon pictus. In The IUCN Red List of Threatened Species 2012. dx.doi.org/10.2305/IUCN. UK.2012.RLTS.T12436A16711116.en [accessed 7 October 2019]. 